\title{
Multifrequency and Multipolarization Radar Scatterometry of Sand Dunes and Comparison With Spaceborne and Airborne Radar Images
}

\author{
Ronald Blom and Charles Elachi \\ Jet Propulsion Laboratory, California Institute of Technology, Pasadena, California
}

\begin{abstract}
Understanding the unusual radar scattering characteristics of sand dunes is necessary in the analysis of radar images of aeolian landscapes of the earth and of other planets. In this paper we report on airborne radar scatterometer data of sand dunes, acquired at multiple frequencies and polarizations. Radar backscatter from sand dunes is very sensitive to the imaging geometry. At small incidence angles the radar return is mainly due to quasi-specular reflection from dune slopes favorably oriented toward the radar. A peak return usually occurs at the incidence angle equal to the angle of respose for the dunes. The peak angle is the same at all frequencies as computed from specular reflection theory. At larger angles the return is significantly weaker. The scatterometer measurements verified observations made with airborne and spaceborne radar images acquired over a number of dune fields in the United States, central Africa, and the Arabian peninsula. The imaging geometry constraints indicate that possible dunes on other planets, such as Venus, will probably not be detected in radar images unless the incidence angle is less than the angle of repose of such dunes and the radar look direction is approximately orthogonal to the dune trends.
\end{abstract}

\section{INTRODUCTION}

Sand seas and sand sheets cover a large percentage of the desert regions of the world [cf. McKee, 1979]. Dunes also cover a substantial area on Mars [Cutts and Smith, 1973; Breed et al., 1979] and may occur on Venus. Because of the increasing use of spaceborne imaging radars to observe and monitor the earth's surface and the necessary use of radar to map the Venusian surface, it is important to understand fully the radar signature of sand dunes.

This study is a part of a larger effort undertaken to determine the radar backscatter characteristics of various geologically interesting surfaces as a function of frequency, incidence angle, and polarization. This information is useful for radar image interpretation, for understanding of physics of radar scattering, and for system definition of future imaging radars. Sand dunes are interesting because they represent a smooth or radar dark natrual surface, yet have topographic characteristics which yield unusual backscattering behavior.

Data from scatterometers can be used to predict the appearance of radar images derived from imaging systems with similar specifications. Since most radar images acquired to date are not radiometrically calibrated, conclusions drawn from comparison of images of the same surfaces made with different imaging radars are limited. This is especially true if the images were acquried on different dates. Scatterometers, of course, make no images. In the present application we are interested in studying the radar backscattering characteristics of sand dunes at the various incidence angles, wavelengths, and polarizations. The scatterometer system used here covers a wider range of wavelengths, polarizations, and incidence angles than any currently available imaging radars. The scatterometer system also brackets the $12-\mathrm{cm}$ wavelength to be used by the Venus Radar Mapper (Magellan).

In this paper we report on the backscatering behavior of sand dunes at four frequencies and four polarization states.

Copyright 1987 by the American Geophysical Union.

Paper number 6B5916.

0148-0227/87/006B-5916\$05.00
Airborne scatterometer data were acquired over a number of dune fields in the southwestern United States. Data covering the Algodones and Kelso dunes in southern California were selected for study. The scattering mechanisms of sand dunes are discussed using models of scattering from flat plates and slightly rough surfaces. Finally, examples of radar images are presented and discussed in order to illustrate how our results apply to the interpretation of images from previous spaceborne radar experiments which include Seasat, SIR-A (Shuttle Imaging Radar), and SIR-B and also to future missions such as the Venus Radar Mapper and SIR-C.

\section{ScatTerometer System aNd Data}

A radar scatterometer is a device which transmits a radar pulse and measures the strength of the echo returned to the instrument from a target. By varing the angle between the target and the antenna of the scatterometer it is possible to determine the strength of the radar echo as a function of the geometry between the target and the radar. This measurement has particular application to imaging radars, as considerable effects are noted in radar images as a function of the angle between the radar beam or illumination and certain terrain types, such as sand dunes. This illumination angle is referred to as the "incidence angle" when measured between the projection of the surface normal and the radar beam. This angle is complementary to the angle indicated by the term "depression angle," which is commonly used in reference to airborne radars. A scatterometer therefore provides information on the radar reflectivity of surfaces at different angles at whatever frequencies and polarizations the instrument can make measurements.

The data reported on herein were acquired from the NASA four-frequency, four-polarization scatterometers mounted on a C-130 aircraft. The essential characteristics of the system are summarized in Table 1. Two polarization states are possible at a time. Hence flight lines must be repeated to acquire the complete horizontal and vertial polarization diversity. Owing to the difficulties of flying precisely the same line, caution is required when comparing vertically and horizontally polarized data of nonhomogeneous terrains. Spatial resolution is 
TABLE 1. Scatterometer System Summary

\begin{tabular}{|c|c|c|c|c|}
\hline & \multicolumn{4}{|c|}{ Frequency } \\
\hline & $\begin{array}{c}400 \\
\mathrm{MHz}\end{array}$ & $\begin{array}{c}1.6 \\
\mathrm{GHz}\end{array}$ & $\begin{array}{l}4.75 \\
\mathrm{GHz}\end{array}$ & $\begin{array}{c}13.3 \\
\text { GHz }\end{array}$ \\
\hline Wavelength, cm & 75 & 19 & 6.3 & 2.3 \\
\hline Band & $\mathbf{P}$ & $\mathbf{L}$ & C & $\mathbf{K u}$ \\
\hline Polarizations* & 4 & 4 & 4 & VV only \\
\hline Incidence angles, deg & $5-50$ & $5-50$ & $5-50$ & $5-50$ \\
\hline Antenna beam width $\dagger$ & 12 & & & 2.5 \\
\hline Resolution $\ddagger$ & $98 \mathrm{~m}$ & $73 \mathrm{~m}$ & $24 \mathrm{~m}$ & $20 \mathrm{~m}$ \\
\hline
\end{tabular}

*HH, HV, VV, VH, one like and one crossed polarization at a time (HH, horizontal transmit and receive; HV, horizontal transmit, vertical receive).

†Across track beam width in degrees

$\ddagger$ Across track at $460 \mathrm{~m}$ altitude, $5^{\circ}$ incidence angle. Along-track resolution is doppler filtered to $73 \mathrm{~m}(400 \mathrm{MHz})$ and $36 \mathrm{~m}$ (others).

largely a function of altitude, and a minimum safe altitude was flown for each site to insure minimum footprint size for the scatterometers. The resolution of the different channels is not identical in the across-track dimension. This is a problem in comparing dune scatterometer data from differing frequencies as the small-scale structure of the dunes responsible for the backscattering behavior can vary greatly over short distances. Resolution also varies as a function of incidence angle in the across-track dimension due to the radar beam fanning out with increasing distance to the target. Resolution in the alongtrack dimension is controlled by Doppler filtering. Thus even with the near simultaneity and coincidence of the scatterometer data, backscatter measurements from precisely the same locations in space and in time are not possible. Data presented here are, however, a substantial improvement over those which were previously available.

A further consideration is the fact that the wavelengths for two of the scatterometers are close, but not identical, to the radar imaging systems to which they are here compared. The $\mathrm{L}$ band scatterometer has a wavelength of $19.0 \mathrm{~cm}$, while the Shuttle Imaging Radars have wavelengths of $23.5 \mathrm{~cm}$. The Ku band scatterometer has a wavelength of $2.25 \mathrm{~cm}$ as opposed to the $X$ band images, which are from a $3.0-\mathrm{cm}$ wavelength system. These small differences in wavelength do not affect the conclusions reached, as the scattering behavior of dunes will be seen to be insensitive to the wavelengths under consideration.

A basic description of the scatterometer system is given by Reid [1975]. Description of the scatterometer data processing hardware is given by Classen et al. [1979], and a software description is given by Clark and Newton [1979] and Clark and Jean [1980].

\section{SANd Dunes: Scatterometry AND RADAR IMAGeS}

This section presents scatterometer data and radar image data from two dune fields which exemplify the range of effects observed. The dune fields are the Algodones and Kelso in the Mojave Desert of California. Dune field locations are shown in Figure 1. A variety of dune types and vegetation cover densities are sampled.

A previous study of radar images of sand dunes was made by Blom and Elachi [1981]. Conclusions reached based on analysis of $L$ and $X$ band images $(23.5-$ and $3.0-\mathrm{cm}$ wave- length, respectively) were that unvegetated sand dunes behaved as quasi-specular reflectors returning energy to the imaging system only when a dune face several wavelengths on a side was nearly perpendicular to the radar beam. Consequently, sand dunes are highly directional features as far as radar imaging is concerned. The interaction of radar imaging geometry and dune geometry results in a radar image of the dunes only being formed if the incidence angle $\left(90^{\circ}\right.$ minus depression angle) is less than or equal to the steepest dune slopes $\left(\sim 34^{\circ}\right)$. If there are no dune slopes near perpendicular to the radar beam either due to the incidence angle being too high or due to the dune trends being at oblique angles to the radar, the radar image will be dark and no mapping of the dunes will be possible.

The effects of the relationship between the dune trends and the radar look direction can be considerable (to the point of making the dunes invisible in some cases) and are documented by Blom and Elachi [1981]. The effect of the dune trend being at an angle to the radar is primarily to reduce the backscattered echo as the dunes become more parallel to the radar beam. Because it is diflicult to study the effects of the angle between the dune trends and the radar beam with the scatterometer data due to the field of view of the scatterometer increasing with incidence angle, here we consider only dunes with trends nearly perpendicular to the radar scatterometer look direction.

Exceptions to the simple specular scattering model can occur if the dunes are vegetated, in which case the radar response is modulated by the interaction of the dune slopes and the vegetation cover or if the dunes have other radar reflective cover on them, such as melting snow. Also, the low dielectric constant of dry fine-grained material such as sand can result

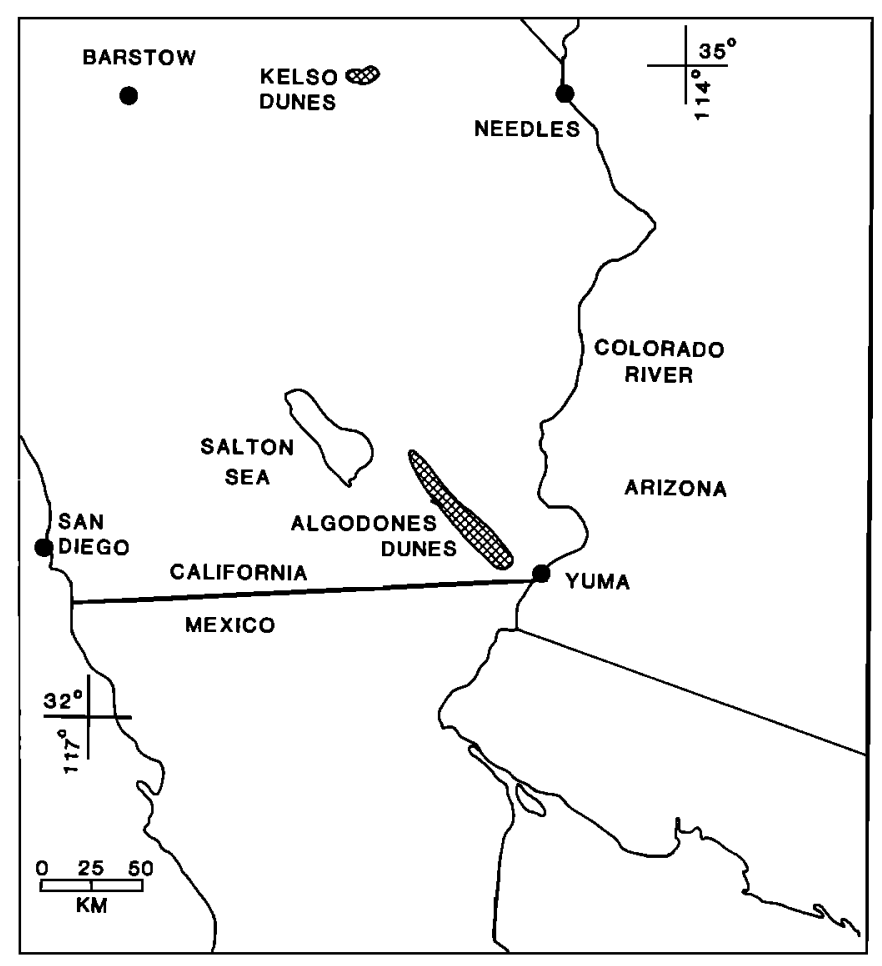

Fig. 1. Location map showing the location of the Kelso and Algodones dunes (cross-hatched) studied with the scatterometer data. 


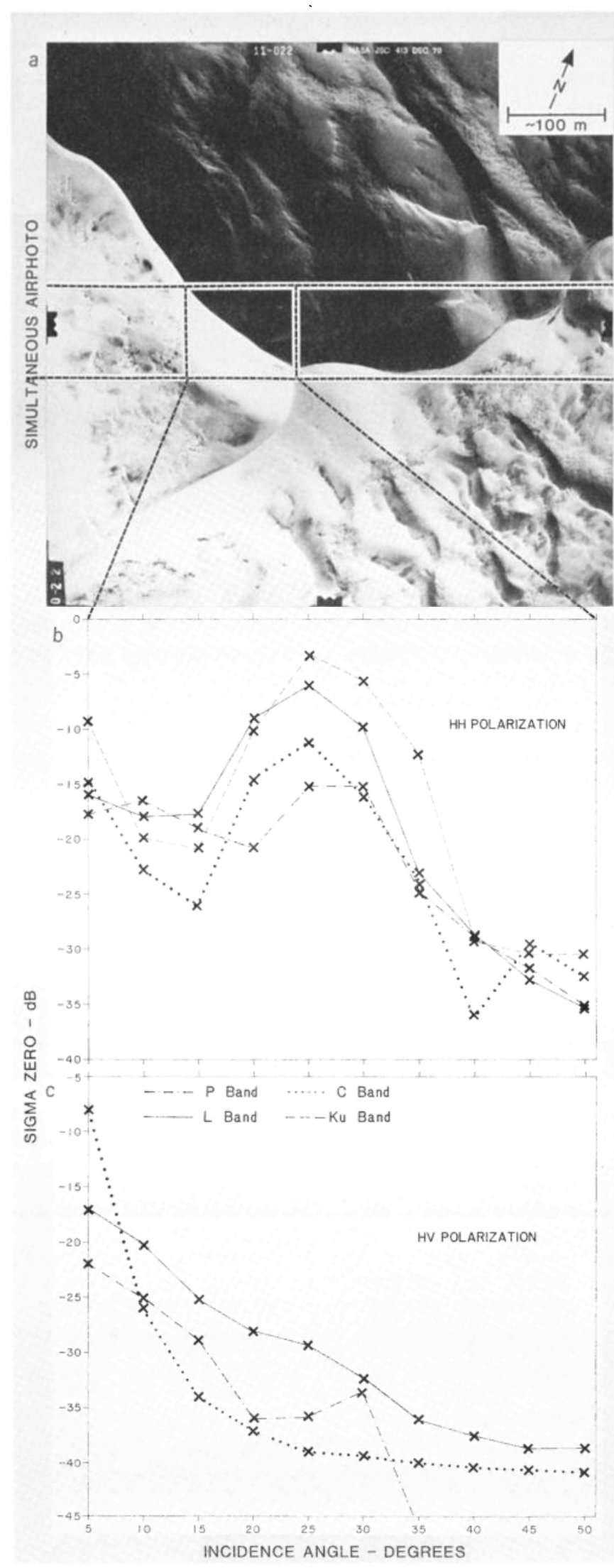

in the sand being relatively transparent to the radar. Subsurface imaging through fine-grained material to depths of several meters have been demonstrated in Seasat, SIR-A, and SIR-B images of arid areas [McCauley et al., 1982, 1986; Blom et al., 1984; Elachi et al., 1984; Berlin et al., 1985, 1986]. The specular echo still occurs from dry dunes; it is simply weaker. This will be discussed further below. Hence dry dunes, such as in the Sahara or on Venus can be mapped if and only if the imaging geometry is favorable.

The dielectric constant of potential aeolian material on Venus cannot be stated with certainty, but it is quite unlikely that it is significantly different from terrestrial aeolian material. Campbell and Ulrichs [1969] present measurements of the dielectric constants of many geological materials, and the values measured are all remarkably similar. There are many papers which are concerned with the dielectric properties of fine-grained materials [e.g., DeLoor, 1983; Hoekstra and Delaney, 1974; Wang and Schmugge, 1980]. The principal factor which changes the dielectric constant of such materials is the water content, which is not a factor in the Venusian environment. Blom [1984] gives an annotated bibliography which includes these references.

Of importance is that fact that a specular echo occurs at the air/dune interface regardless of the moisture content of the dunes, and this presents the possibility that dry sand dunes could be mapped at low incidence angles, where the specular echo is reflected to the radar, and the subdune surface could be mapped at higher incidence angles, where the surface echo is not reflected back toward the radar (presuming the subsurface presented a scattering contrast; see Blom et al. [1984] for a review of the conditions which permit subsurface radar imaging).

This incidence angle effect might also provide a mechanism for distinguishing between surface and subsurface features on radar images when variable incidence angle images of suitable areas become available.

With the exception of extremely dry areas such as the Sahara, terrestrial sand dunes tend to be damp due to the fact that the size sorting of aeolian sand is such that capillary action does not occur [Sharp, 1966]. Hence for dunes in localities with occasional rainfall the dunes stay damp below the surface and have a slightly higher complex dielectric constant. The best aeolian planetary analogues from a radar standpoint are therefore in the very dry parts of the earth such as the Sahara. These considerations may prove important in the analysis of Venus Radar Mapper images. Any sand on Venus will, of course, be dry.

Fig. 2. (opposite) (a) An air photo taken simultaneously with the scatterometer data plotted below it. The scatterometers sampled the horizontal swath across the center of the photo indicated by the parallel lines. Flight direction was from left to right, and the scatterometers scanned aft. $(b)$ and $(c)$ The data plotted are from the boxed in area in the left center of Figure $2 a$. The shorter-wavelength scatterometers sampled a narrower area within the box. The horizontally polarized transmit and receive scatterometer data $(\mathrm{HH})$ from the large dune are shown Figure $2 b$. Note that the backscatter peaks at about $25^{\circ}$, where the local incidence angle at the dune face is zero. The cross-polarized scatterometer data for the same location are shown in Figure $2 c$. In general, the dunes are weak depolarizers, and little cross-polarized signal is returned. 


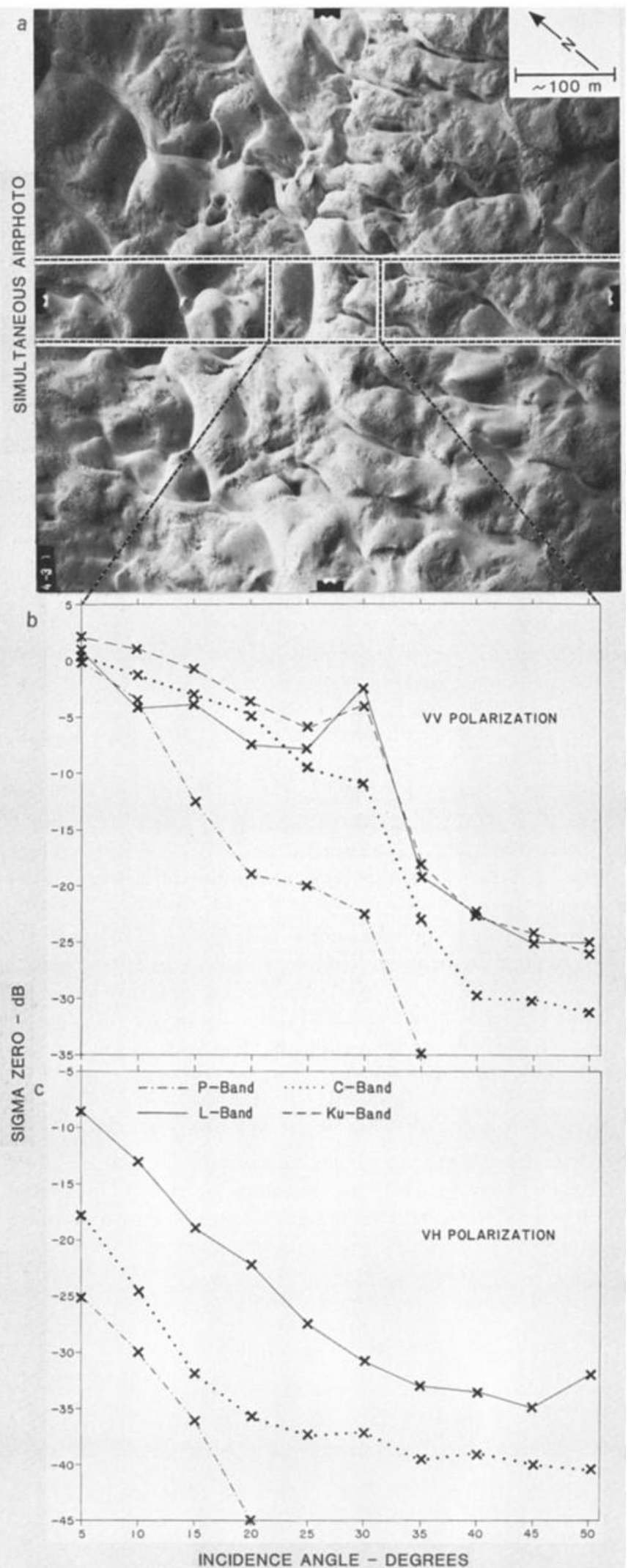

Fig. 3. Vertically polarized scatterometer data from the recently formed dune crest in the center of the air photo (Figure 3a). As in Figure 2, the scatterometer data cover the swatch indicated by the horizontal lines across the center of Figure 3a. Flight direction was from left to right, and the scatterometers scanned aft. The data shown are from the boxed in area in Figure $3 a$. The like-polarized data are shown in Figure 3b, and the cross-polarized data are shown in Figure $3 c$. Note the reflection peak at about $35^{\circ}$ in the like-polarized data.
Another factor which may influence radar backscatter from dunes is sand ripples. Measurements of sand ripples indicated that their periodicities and amplitudes were inadequate to cause either Bragg or Rayleigh scattering at wavelengths as short as $3 \mathrm{~cm}$ (X band) [Blom and Elachi, 1981]. Granule ripples (megaripples) on the earth can be of sufficient amplitude and wavelength to cause backscattering (a megaripple is a very large ripple with a wavelength in excess of $10 \mathrm{~m}$; see Greeley and Iverson [1985]). We have not studied any areas which have large ripples covering a sufficient number of radar resolution cells to be imaged. Greeley et al. $[1980,1984 a]$ and White [1981] conclude that the atmospheric conditions on Venus would produce short, low-amplitude ripples and bedforms. Consequently, it seems unlikely that Venusian megaripples will be detectable in Venus Radar Mapper images. Other aeolian bedforms which might occur on Venus include small parallel grooves and ridges [Greeley and Marshall, 1985] created by rolling (rather than saltation) of grains. Such bedforms would, like dunes, have highly directional radar scattering properties and might be strong reflectors if the imaging geometry were favorable and they were large enough.

The essential characteristics of radar scattering from sand dunes can be best visualized by studying the backscatter from a single large unvegetated dune. The examples here are from the interior portions of the Kelso Dunes. Figure $2 a$ is an air photo acquired simultaneously with the scatterometer data plotted in Figures $2 b$ and $2 c$. This single dune is about $160 \mathrm{~m}$ high and has a slope of about $25^{\circ}$.

The like-polarized ( $\mathrm{HH}$, horizontal polarized transmit and receive) scatterometer curves in Figures $2 b$ all have very similar shapes, with backscatter at about $-15 \mathrm{~dB}$ at $5^{\circ}$ incidence angle, decreasing at slightly larger angles, and then rapidly increasing to -5 to $-10 \mathrm{~dB}$ at $25^{\circ}$ incidence angle, which corresponds to normal incidence at the dune surface. This explains why the dune has greatest backscatter at this angle. Detail differences in the scatterometer curves are probably due to the differing fields of view of the various scatterometers, the antenna pattern effects, and the area of the dune faces relative to the radar observation wavelength. The cross-polarized (HV, horizontal transmit and vertical receive) scatterometer data in Figure $2 c$ show a rapid decrease in backscatter with increasing angle $(75 \mathrm{~cm}$ HV data had a very low signal-to-noise ratio; hence they are of poor quality and not shown).

Figure 3 is similar to Figure 2 and shows another, smaller dune for which we have vertically polarized data. The VV data in Figure $3 b$ show the backscatter declining slowly from about $0 \mathrm{~dB}$ to about $-5 \mathrm{~dB}$ for the $19.0-, 6.3-$, and $2.25-\mathrm{cm}$ scatterometers ( $\mathrm{L}, \mathrm{C}$, and $\mathrm{Ku}$ bands, respectively). The 75-cm ( $\mathrm{P}$ band) data show a rapid decline to about $-20 \mathrm{~dB}$. The three shorter wavelength scatterometers record a rise in backscatter at $30^{\circ}$, equaling the backscatter at $5^{\circ}$, followed by a very rapid decrease to -25 or $-30 \mathrm{~dB}$ at larger incidence angles. This dune is considerably smaller than the one in Figure 2 and apparently small enough that it is not a good reflector at $75-\mathrm{cm}$ wavelength. The $75-\mathrm{cm}$ wavelength data do not have a strong backscatter peak at $30^{\circ}$. The VH data shown in Figure $3 c$ decrease rapidly in reflectivity, and the $19.0-\mathrm{cm}$ crọsspolarized backscatter is considerably stronger than the $6.3-\mathrm{cm}$ cross-polarized backscatter (the $75-\mathrm{cm}$ cross-polarized data were again of poor quality).

Figures $4 b$ and $4 c$ show a set of backscatter curves for the dune seen in Figure 4a. This dune has had its profile modified 


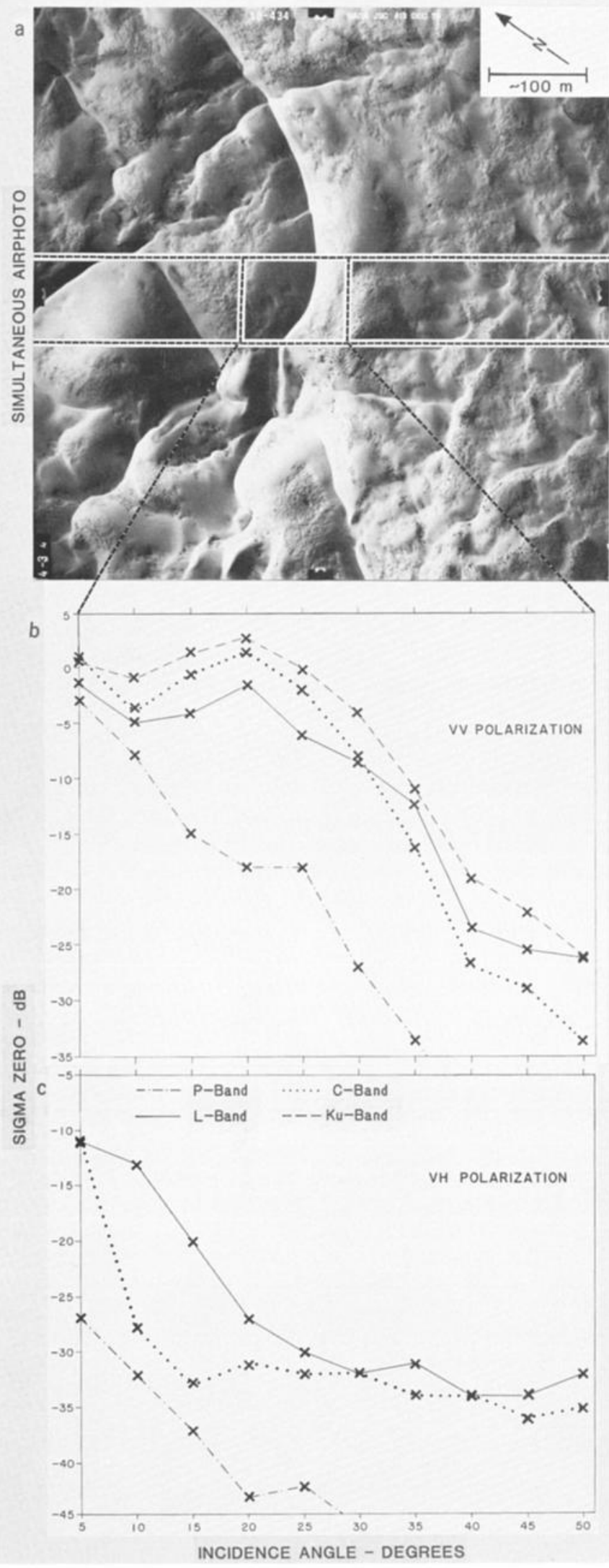

Fig. 4. Vertically polarized data from a dune whose profile has been recently modified by a change in the wind direction. The scatterometer data plotted are from the area boxed in the center of Figure $4 a$. Flight direction was again from left to right. Note that the peak radar reflection occurs at a lower angle than for the dunes in Figures 2 and 3. by a seasonal change in the wind direction. The effect of the modification on the dune can be seen in the VV backscatter data shown in Figure $4 b$ as a smoother angular response, with the backscatter peak occurring at about $20^{\circ}$. Data from the three shorter-wavelength scatterometers have a similar response, with the shortest-wavelength data having the strongest backscatter. The longest-wavelength data show a much lower backscatter, perhaps due to the dune area observed by the scatterometer being too small to make a satisfactory reflector. Alternately, the lower backscatter could be due to the effects of penetration and a moisture gradient within the dune sensed by the $75-\mathrm{cm}$ system. The cross-polarized data (VH in Figure $4 c$ ) indicate a rapid decline in backscatter, with the $19.0-\mathrm{cm}$ wavelength recording the strongest backscatter.

The scatterometer data presented indicate that the backscatter from a sand dune is due to quasi-specular reflection from the flat (from a radar wavelength point of view) dune faces. Consequently, the angular behavior of the backscatter is a very strong function of the dune slopes.

In order to explain the general behavior of the backscatter from a dune field, we can consider the backscatter behavior of a flat surface of dimensional $L$ and slope $\gamma$ (refer to Figure 5). We consider only the case of a one-dimensional surface. The results can be generalized to the case of two dimensions, however [Kerr, 1951; Fung and Ulaby, 1983].

The incident wave will generate a reflected field at the surface of the interface equal to

$$
E_{s}=E_{i} R\left(\theta_{i}-\gamma\right) \exp \left\{i\left[k x \sin \left(\theta_{i}-\gamma\right)\right]\right\}
$$

where $R$ is the Fresnel reflection coefficient, $E_{l}$ is the incident field at the surface, $\theta_{i}$ is the look angle and $k=2 \pi / \lambda(\lambda$ is radar wavelength). This surface field distribution leads to a normalized backscatter cross section given by [Fung and Ulaby, 1983]

$$
\sigma\left(\theta_{i}, \gamma\right)=4 \pi \frac{A}{\lambda^{2}} R^{2}\left[\frac{\sin \left[k L \sin \left(\theta_{i}-\gamma\right)\right]}{k L \sin \left(\theta_{i}-\gamma\right)}\right]^{2} \cos ^{2}\left(\theta_{i}-\gamma\right)
$$

where $A$ is the area of the flat plate. This formula is valid for $\left(\theta_{t}-\gamma\right)$ in the range of $0^{\circ}-50^{\circ}$ which is the applicable range for the data in this paper. At larger angles, polarization effects may become significant [Ross, 1966]. The expression can be

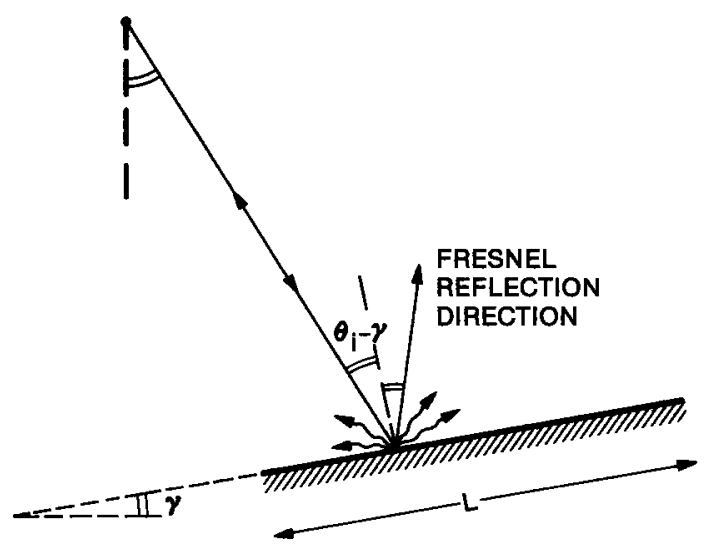

Fig. 5. Geometric arrangement showing the scattering of a wave with look angle from a flat surface of size $L$ and slope $\gamma ; \psi$ is the angle of the received wave relative to the Fresnel reflection direction. In the case of backscatter, $\psi=2\left(\theta_{1}-\gamma\right)$. 

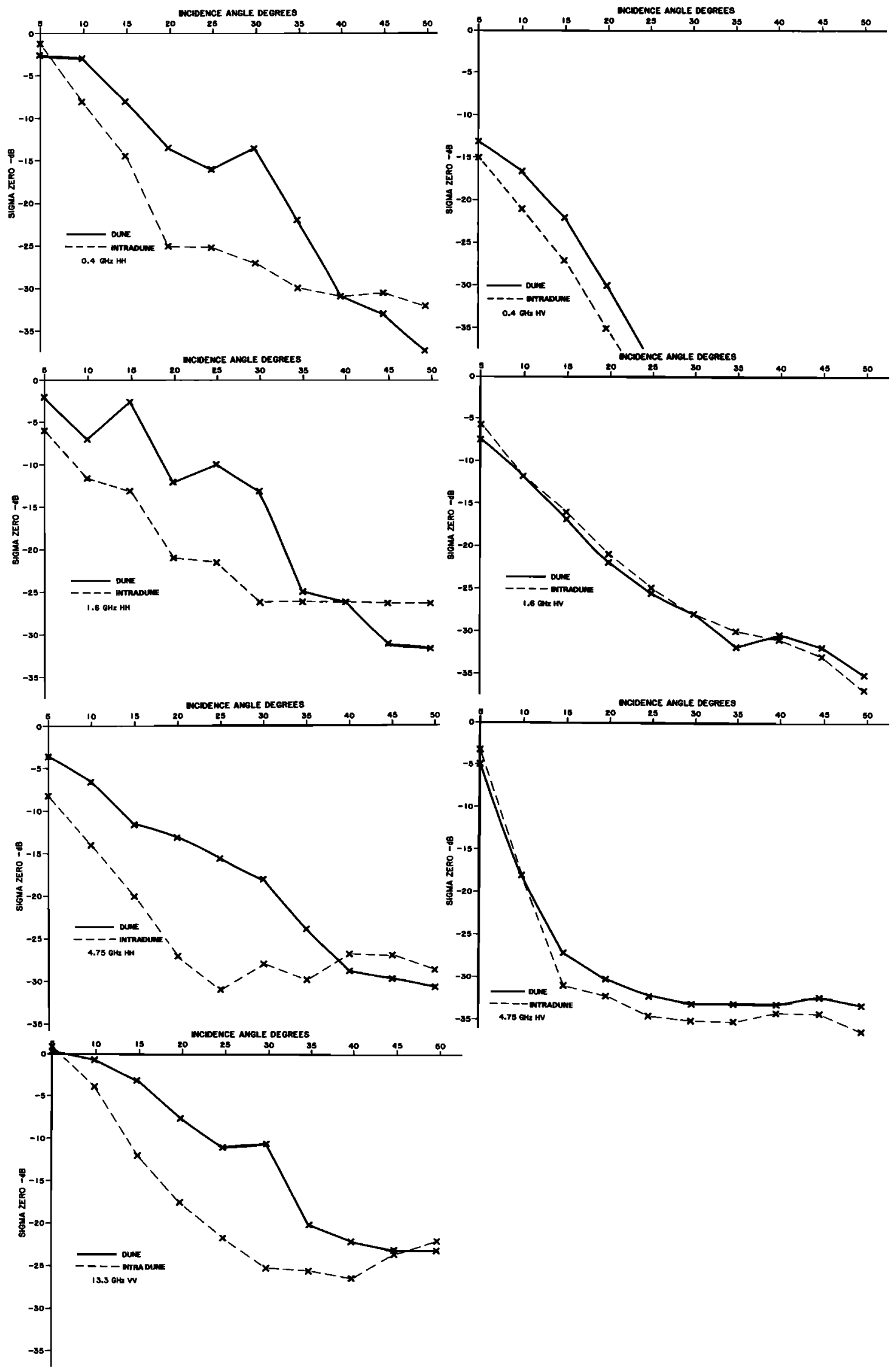

Fig. 6. Scattering contrasts between dune and intradune areas at the Algodones Dunes are plotted for each frequency as a function of angle. In each case, the intradune flat is a stronger scatterer at higher incidence angles, while the dunes are stronger scatterers at lower incidence angles. This behavior is not a function of frequency over the range studied. 


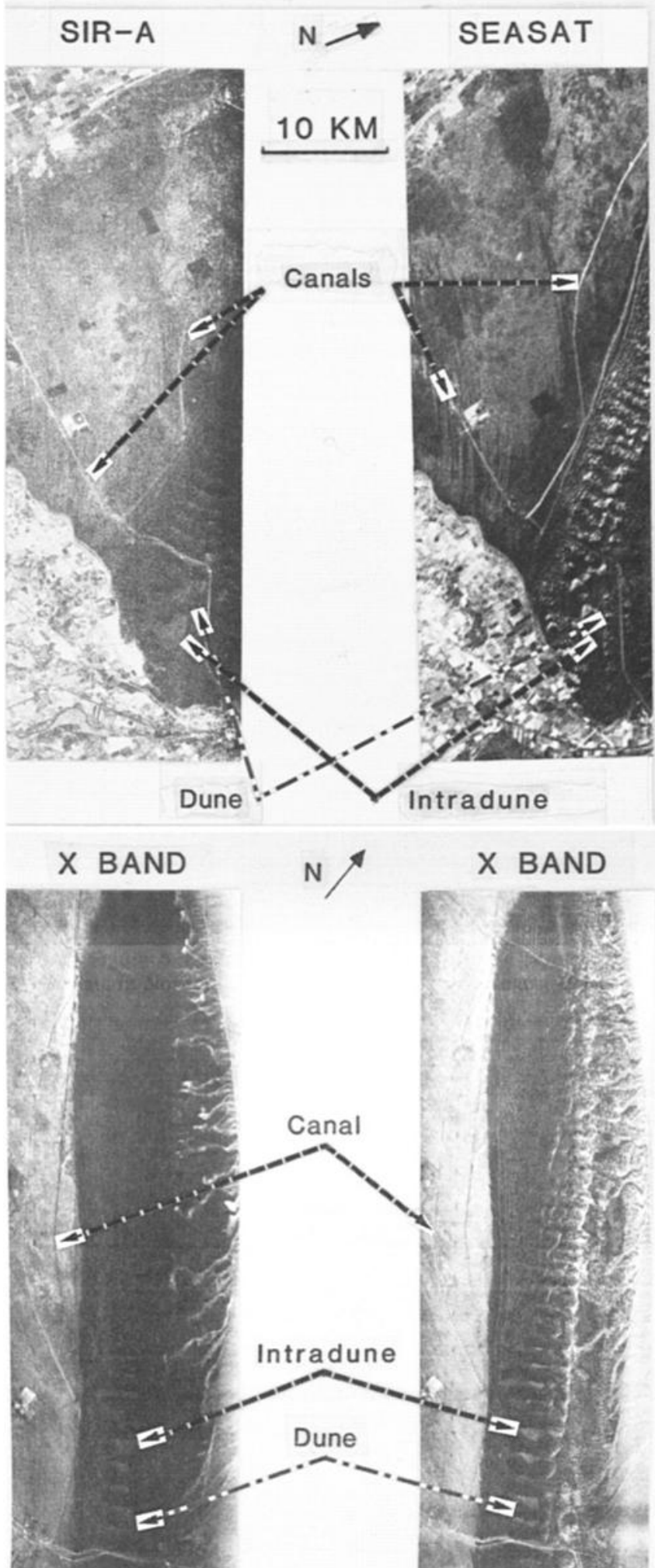

Fig. 7. Radar images of the Algodones Dunes. Orientations and coverage of the upper and lower image pairs are slightly different. The orbital images only cover the southern part of the dunes. The north arrows and the canals indicated are for orientation purposes. The top images are orbital $\mathrm{L}$ band $(23.5-\mathrm{cm}$ wavelength) and the bottom images are airborne $X$ band (3-cm wavelength). The left images were made with incidence angles of greater than $40^{\circ}$, while the right images were made with smaller incidence angles. Comparison of these images shows that the dunes backscatter only at smaller incidence angles, while the intradune areas become brighter than the dunes at larger incidence angles. This behavior is as indicated by the scatterometer data in Figure 6. Seasat data were acquired in late summer 1978, SIR-A data in November 1981, and X band data in August 1981. generalized for a two-dimensional plate [Kerr, 1951; Fung and Ulaby, 1983].

The above expression for $\sigma$ has a $\sin x / x$ pattern, with a central lobe of angular width $\psi$ equal to (for $\lambda \gg L$ )

$$
\psi=4 \pi / k L=2 \lambda / L
$$

If the flat surface is such that the incident wave is orthogonal to it (i.e., $\theta_{i}=\gamma$ ), the backscatter return is maximum. However, even if $\theta_{i} \neq \gamma$ but still such that

$$
\left|\theta_{i}-\gamma\right|<\psi / 2
$$

a strong backscatter will occur.

In actuality, the surface has a statistical distribution of flat surfaces of different sizes $L$ and different slopes $\gamma$. In the case of sand dunes the maximum slope (the angle of repose) is about $34^{\circ}$. Thus it is expected that a peak will occur at an angle less than $34^{\circ}$ and the peak width will depend on the ratio $\lambda / L$ and the distribution of $L$ and $\gamma$. Hence it is expected to be a relatively broad peak. As the wavelength gets longer, the peak will be less pronounced. This is observed in most of the acquired data where the $75-\mathrm{cm}$ wavelength peak is the least pronounced.

As we increase the frequency, the ratio $\lambda / L$ becomes smaller, leading to the conclusion that the peak will be sharper and more pronounced. However, as the wavelength gets shorter, the surface roughness would tend to have a larger effect, leading to a broadening of the beam again. This might explain why, in some situations, the $2.25-\mathrm{cm}$ peak is not as pronounced as the $6.3-$ or $19.0-\mathrm{cm}$ peaks.

Previous analysis of radar images [Blom and Elachi, 1981; Blom et al., 1982a, b] and the data discussed below indicate that this very simple scattering mechanism is applicable to all dunes observed. In order to capture enough signal to make an image of an unvegetated dune field, the incidence angle must be low enough that some of the quasi-specular echo is reflected to the sensor. However, there are two other common situations which can allow mapping of dune fields using radar images. The first case is vegetated dune fields, where it is the vegetation which provides most of the backscattered energy The second case is dunes which reside on a substrate sufficiently rough to provide backscatter adequate to outline the dunes with a bright image tone. These two situations are discussed below.

\section{Algodones Dunes}

The Algodones Dunes are located in southeastern California and make up one of the largest active dune fields in the United States (Figure 1). These dunes have been studied both from the origin and development standpoint and also a planetary geology perspective [Smith, 1970; Cutts and Smith, 1973; Breed, 1977; Sharp, 1979].

The radar data base for the Algodones Dunes has expanded since our earlier publication [Blom and Elachi, 1981]. It now includes, in addition to the scatterometer data, $3.0-\mathrm{cm}$ wavelength $\mathrm{HH}$ and $\mathrm{HV}$ airborne radar images from two ranges of incidence angles and also Shuttle Imaging Radar (SIR-A) images. The latter data are comparable in wavelength (23.5 $\mathrm{cm})$ to Seasat but have a larger incidence angle $\left(47^{\circ}\right.$ versus $23^{\circ}$ ). These additional data allow comparison of the scatterometer data to radar images to show the potential effects of varying the frequency, look angle, and polarization of radar imaging systems.

A feature of the Algodones Dunes which makes them useful 


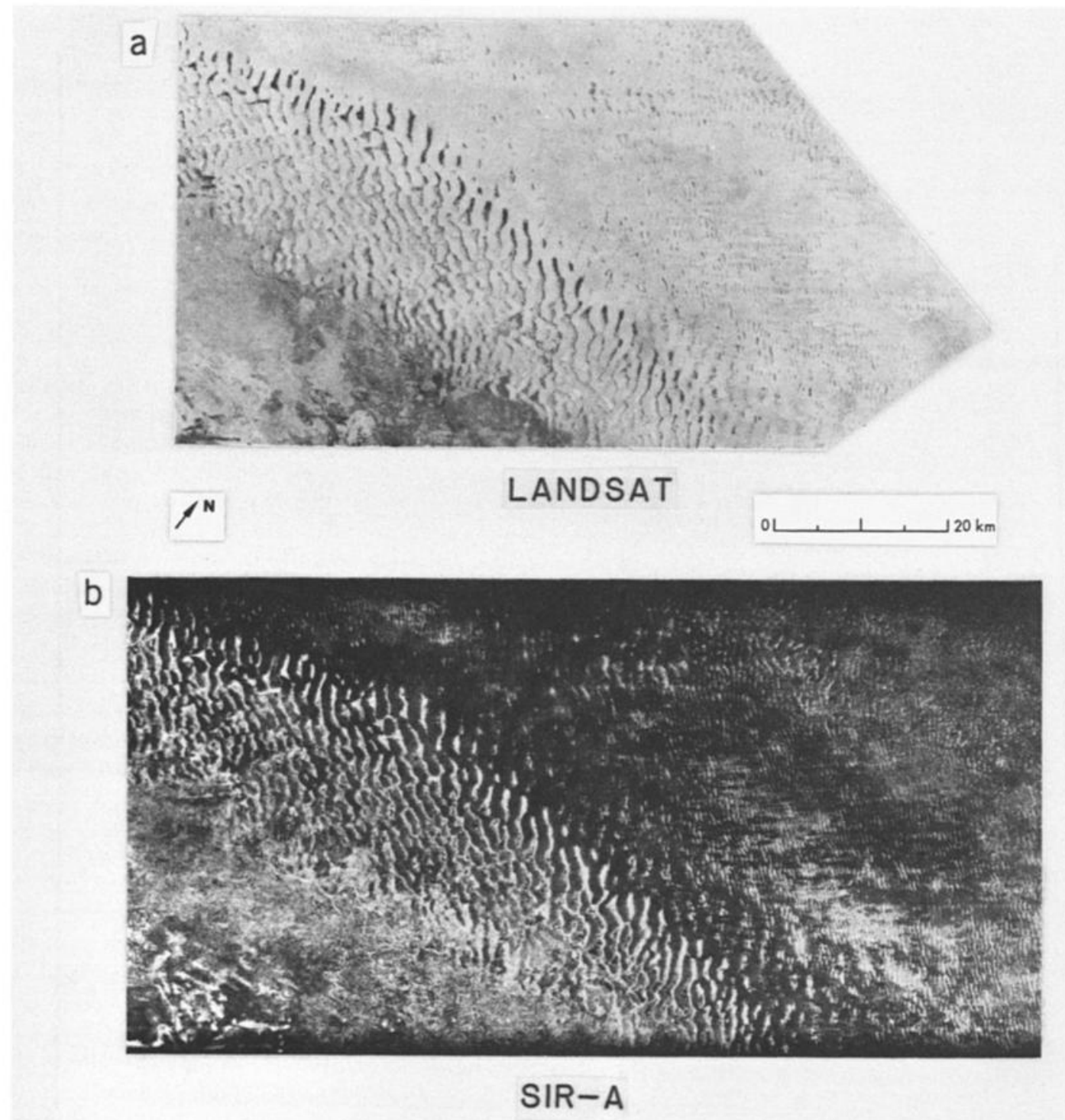

Fig. 8. (a) Landsat band 5 image of a large expanse of sand dunes near Lake Chad in Africa (acquisition date February 15, 1975). The darker areas in the Landsat image are vegetated intradune flats (vegetation is dark in MSS band 5). (b) SIR-A image of the same area in which the vegetated intradune areas are bright and outline the dunes, but the dunes themselves are dark. Distinction between dune and intradune areas is not possible for the unvegetated areas, where both dune and intradune have very low backscatter and are consequently very dark. SIR-A image acquired November 1981.

for defining radar systems is the presence of intradune flats. The southern portion of the dune field consists of large barchanoid dunes which are separated by relatively sand-free desert floor, the substrate upon which the dunes move. These intradune flats were studied by Sharp [1979]. Although the desert floor is quite smooth, it is rougher than the dune surface and presents a radar scattering contrast. Intradune flats also exist in the Hellespontus dune field on Mars [Cutts and Smith, 1973] and might exist on Venus.

The radar scattering contrasts between the dunes and the intradune flats as a function of frequency and angle can be seen in Figure 6. Note that the dunes have considerably higher backscatter than the intradune flats at incidence angles up to about $35^{\circ}-40^{\circ}$, beyond which the dunes have a lower backscatter than the flats. Also note that the cross-polarized signals are very weak. The differing structure of the dune backscatter data for the different frequencies is attributed to the different fields of view of the scatterometers. The significance and potential practical application of these data become apparent when compared to radar images.

Figure 7 shows radar images of the dunes and intradune flats at two wavelengths and two incidence angles. The upper image pair are $23.5-\mathrm{cm}$ wavelength image from Seasat and SIR-A, both spaceborne systems which differed mainly in incidence angle. The lower image pair are from a $3.0-\mathrm{cm}$ wavelength airborne system flown such that the right image has a range of incidence angles from $14^{\circ}$ to $50^{\circ}$ and the left image from $45^{\circ}$ to $63^{\circ}$. The $3.0-\mathrm{cm}$ wavelength images were collected within a few minutes of each other. The image characteristics that could be predicted on the basis of the scatterometer data are observed in the images. The dunes are bright at small incidence angles (Seasat and right $3.0-\mathrm{cm}$ wavelength image) due to quasi-specular refiections from favorably oriented dune slopes (especially apparent in the higher-resolution aircraft 


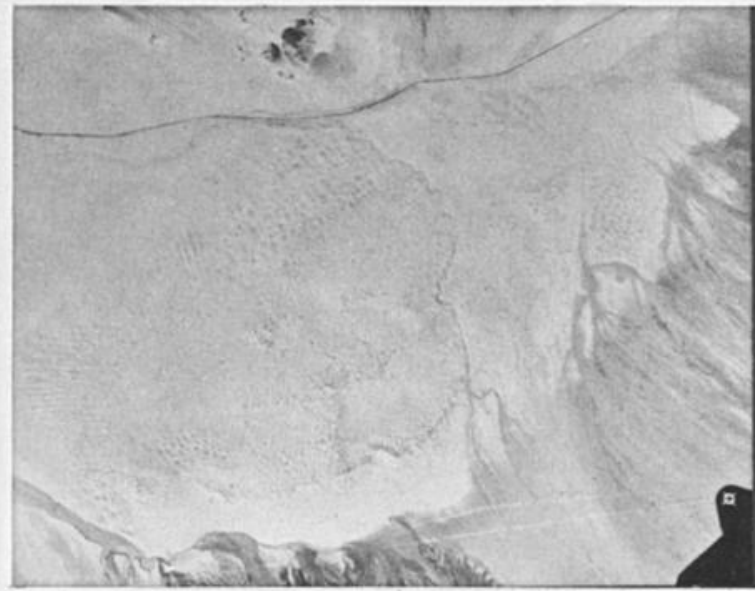

A. AIR PHOTO SUN ILLUMINATION

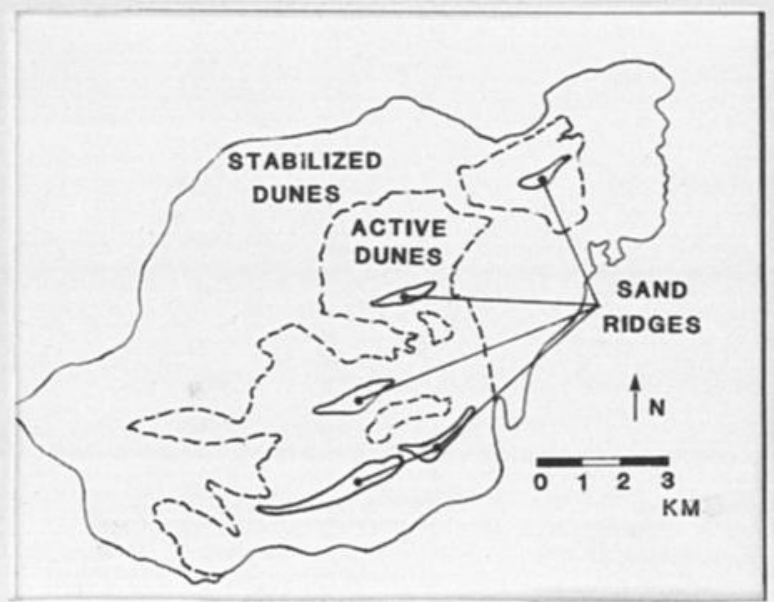

B. SKETCH MAP

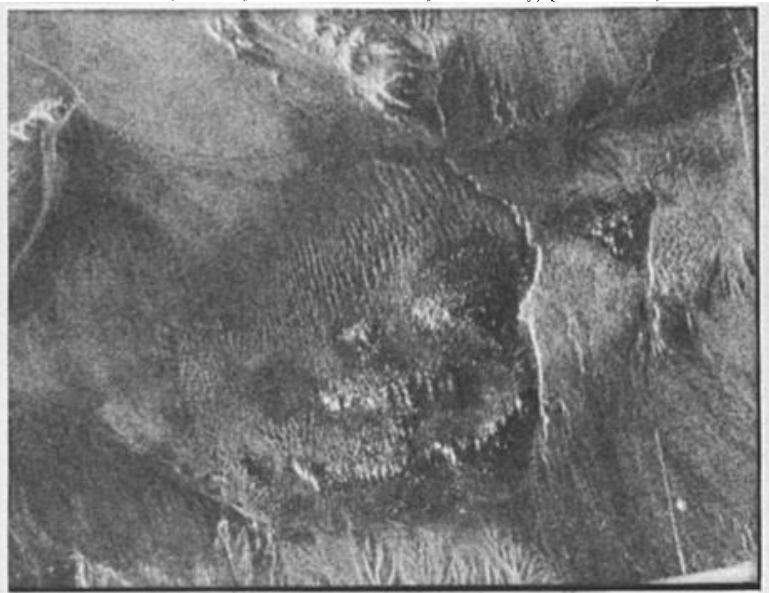

C. SEASAT LOOK DIRECTION $\rightarrow$

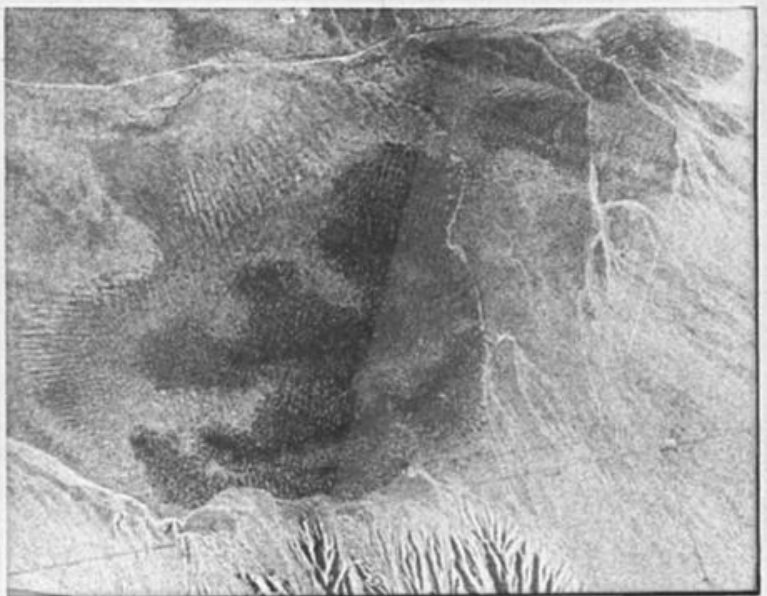

D. X-BAND LOOK DIRECTION

Fig. 9. (a) An air photo of the Kelso Dunes. (b) A sketch map adapted from Sharp [1966]. (c) A Seasat image of the Kelso Dunes. (d) An X band $(3.0 \mathrm{~cm})$ radar image of the same area. Observe the tonal variations in the $\mathrm{X}$ band image and note correspondence of the boundary between the active and stabilized dunes shown on the map to one of the image tone boundaries on the $\mathrm{X}$ band image. The Seasat image is more sensitive to the dune slopes than the vegetation, and less correspondence exists between the Seasat image and the vegetation distribution. Reproduced from Blom and Elachi [1981].

image). No dune forms are recognizable in the higher incidence angle images, although the outline of the dunes can be inferred by the tonal boundary between the dunes and the intradune flats. The look directions for each of the images are indicated on the figure. Although the look directions are not the same for all of the images, the critical point here is that the dunes themselves become invisible when imaged at higher incidence angles. At the higher incidence angles the dunes could not be mapped regardless of their orientation relative to the look direction. See Blom and Elachi [1981] for a more detailed discussion of look direction effects.

Cross-polarized images (HV) are available from the $3.0-\mathrm{cm}$ wavelength aircraft system but are not shown as both the dunes and intradune flats are displayed as very dark area, as can be inferred from the cross-polarized scatterometer data in Figure 6.

In other dune fields with intradune flats the intradune areas are occasionally radar smooth lacustrine deposits which would not show a radar image tone contrast between dune and intradune areas at high incidence angles. In such cases, the entire area would be dark on the radar image. As an example of this situation, Figure $8 a$ is a Landsat band 5 (visible red) image of a large area of dunes north of Lake Chad. These dunes rest upon a substrate of lacustrine deposits left from an earlier, much larger lake called Lake Mega-Chad. In the Landsat image the dunes are bright due to the high reflectivity of the sand. The dark areas are vegetation, growing in the intradune flats (vegetation is dark in the visible red, which corresponds to the Landsat band 5 image). Figure $8 b$ is a SIR-A image of the same area. Note that the bright areas on the SIR-A image correspond to the dark, vegetated areas on the Landsat image. Intradune areas that are vegetation-free on the Landsat image (brighter areas in between the dune forms) are dark on the SIR-A image due to lack of scattering constrast between the dunes, which do not backscatter at the SIR-A incidence angle, and the smooth lacustrine deposits upon which the dunes reside.

\section{Kelso Dunes}

The Kelso Dunes are located in the eastern Mojave Desert of California approximately $110 \mathrm{~km}$ east of Barstow (Figure 1). Seasat and aircraft images of the Kelso Dunes were ana- 

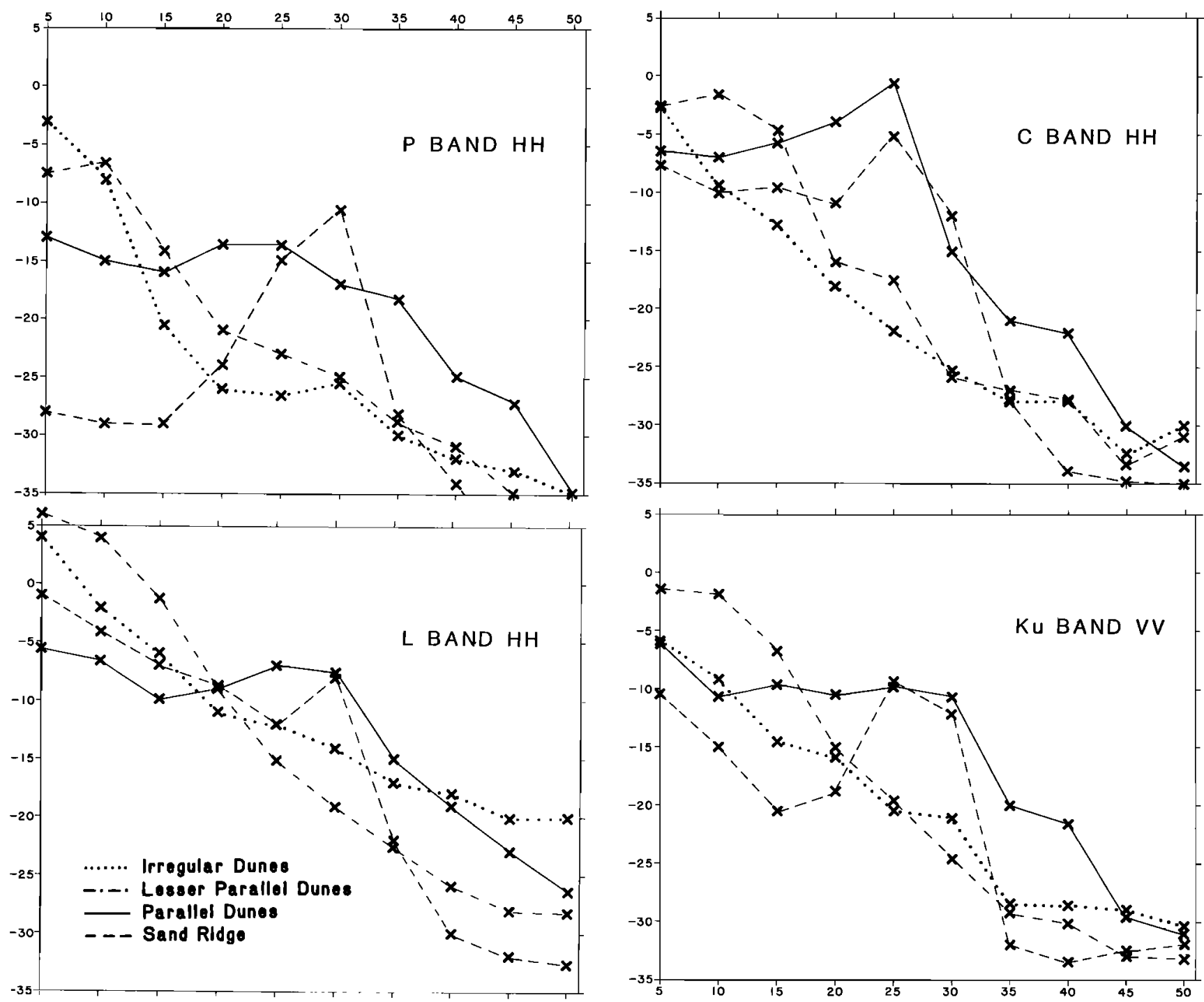

\section{INCIDENCE ANGLE - DEGREES}

Fig. 10. Radar scatterometer data for each of the four tonal as cas identified in the $\mathrm{X}$ band image of Kelso Dunes. The $\mathrm{Ku}$ band scatterometer data (bottom right) are most comparable in wavelength to the $\mathrm{X}$ band image $(2.25$-cm versus $3.0-\mathrm{cm}$ wavelength). The "sand ridge" and "parallel dune" data are from the active portions of the dunes shown in Figure $9 d$. The data for the "lesser parallel dunes" and the "irregular dunes" are from the stabilized part of the dunes indicated in Figure $9 d$. The $50^{\circ}$ incidence angle data are nearest the $65^{\circ}$ incidence angle of the $\mathrm{X}$ band image. See text for discussion.

lyzed by Blom and Elachi [1981], and aircraft images were analyzed by Sugiura and Sabins [1980]. These dunes have been extensively studied and described by Sharp $[1962,1963$, 1966]. Like many dune fields, the Kelso Dunes have a spatially variable vegetation cover. This vegetation cover decreases to zero in the interior of the dune field but is sufficient to stabilize its outer margins. What makes the Kelso Dunes instructive from a radar geology point of view is the sensitivty of radar to the sparse vegetation cover.

Figure 9 shows Seasat $23.5-\mathrm{cm}$ and airborne $3.0-\mathrm{cm}$ radar images of the Kelso Dunes. As previously discussed, the small incidence angle used by the Seasat radar results in specular reflections from the dune faces, which form the image. The $3.0-\mathrm{cm}$ wavelength image was acquired with an incidence angle of about $65^{\circ}$, from which there should be no reflection from the dunes. Comparison of the $23.5-$ and $3.0-\mathrm{cm}$ wave- length images shows some interesting contrasts, particularly with respect to the image tone distribution.

The tonal boundaries seen in the $3.0-\mathrm{cm}$ wavelength image were first noted by Sugiura and Sabins [1980]. Blom and Elachi [1981] ascribed these tonal boundaries to systematic variations in the vegetation density, after noting the very close correspondence of one of the $\mathrm{X}$ band image tone boundaries to the separation between stabilized and unstabilized dunes made in Sharp's [1966] study. Sharp's map is sketched here in Figure $9 b$. In our earlier study we divided the tonal variations in the image into four regions which correspond to the outer, stabilized, irregular and lesser parallel dunes, and the active, unstabilized, parallel dunes and sand ridges in the interior of the dunes. Air photos taken with the scatterometer data were used to determine the amount of vegetation in each of the $3.0-\mathrm{cm}$ wavelength image tonal areas. 


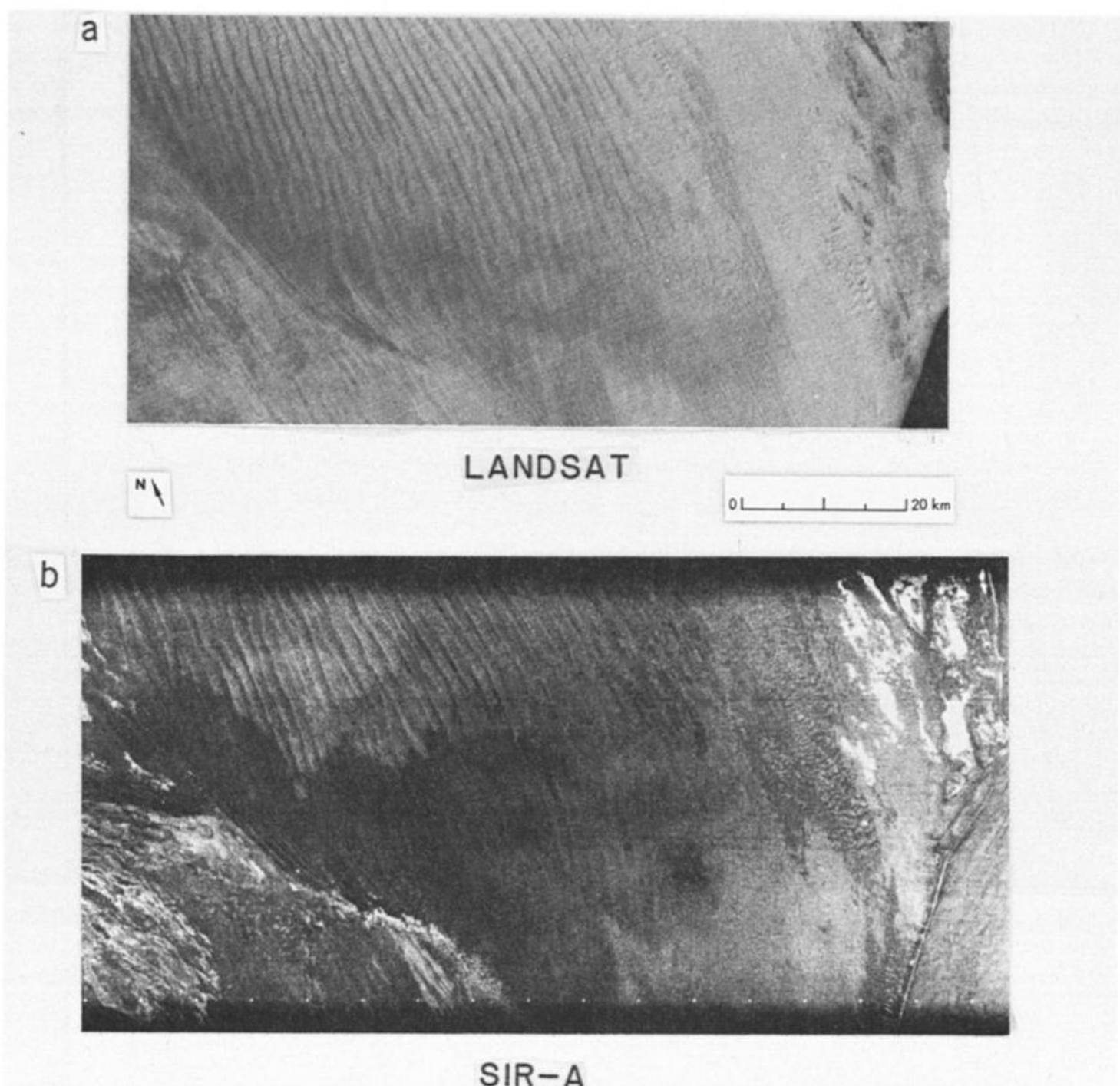

Fig. 11. (a) A Landsat band 7 image of the Wahiba Sands in Oman. (b) A SIR-A radar image. These dunes have a variable vegetation cover which is not easily discerned in this Landsat image (vegetation is bright in MSS band 7 , acquisition date November 26, 1972). In the SIR-A image the dark image tones correspond to the vegetation-free regions, while the brighter areas have a variable vegetation cover. The dunes are easy to discern in the vegetated regions, as the backscatter is from the vegetation and modulated by the dune slopes. SIR-A image acquired November 1981.

The irregular dunes and the lesser parallel dunes have $20-30 \%$ vegetation cover which stabilizes them. The parallel dunes have about $11 \%$ vegetation cover, and the sand ridges have zero vegetation cover. The vegetation consists primarily of short creosote bushes and grass. In order to evaluate the effects of dune vegetation on radar backscatter as a function of radar frequency and look angle, scatterometer data for the vegetation density areas previously defined on the $3.0-\mathrm{cm}$ radar image at Kelso Dunes were studied.

Figure 10 shows like-polarized scatterometer data for the tonal regions seen on the $3.0-\mathrm{cm}$ wavelength image in Figure 9 from each of the four frequencies available. The longestwavelength data are plotted in the top left panel and the shortest-wavelength data are plotted at the lower right panel of Figure 10. The $2.25-\mathrm{cm}$ wavelength data shown in the lower right panel corresponds most closely to the $3.0-\mathrm{cm}$ wavelength image in Figure 9. Because the vegetation cover is sparse and irregular and because the fields of view of the scatterometers change with wavelength and incidence angles, only general comparisons are possible. However, we can make the following observations.

The backscatter from the unvegetated, active sand ridge has the expected peak return around $25^{\circ}$ or $30^{\circ}$ incidence angle and a rapid decrease in backscatter at larger incidence angles at all wavelengths. The highest backscatter in the $25^{\circ}-30^{\circ}$ incidence angle range is always from the dunes with the least vegetation (sand ridge and parallel dunes), indicating the dominance of the quasi-specular scattering in this incidence angle region.

At the largest incidence angle the highest backscatter is always from the irregular dunes (which have the most vegetation) for each wavelength (except at $75 \mathrm{~cm}$, where there is a tie for highest backscatter). The range of backscatter at the highest incidence angle shows that the $19.0-\mathrm{cm}$ data have the largest spread, with the irregular dunes (most vegetation) having the highest backscatter and the sand ridge (no veg- 
etation) having the lowest backscatter. The $6.3-$ and $2.25-\mathrm{cm}$ wavelength data have a smaller backscatter range at the largest incidence angle for the four dune areas studied here.

From these measurements we make the following observations. At incidence angles below about $35^{\circ}$ the primary factor modulating the radar backscatter is the dune slopes. The vegetation certainly contributes to this backscatter, as the highest backscatter in the incidence angle range below about $15^{\circ}$ is usually from the dunes with the most vegetation cover. But the shapes of the curves are largely a function of the dune slopes. Beyond about $35^{\circ}$ incidence angle, the backscatter is mostly from the vegetation cover, as the dunes with the most vegetation have the strongest backscatter. Returning to the original observation made about the $3.0-\mathrm{cm}$ wavelength radar image in Figure 9, it looks like extrapolation of the $2.25-\mathrm{cm}$ wavelength scatterometer data beyond the $50^{\circ}$ maximum in the scatterometer data plot would likely result in a similar backscatter variation distribution to that seen in the $3.0-\mathrm{cm}$ wavelength image.

Considering these observations, it is clear that radar images of vegetated dunes will be quite sensitive to the vegetation cover, especially at larger incidence angles. Because the dune slopes modulate the backscatter even from the vegetation by changing the effective incidence angle, it is obvious that it would not be apparent from examination of a radar image that in fact, the backscatter may be coming from a vegetation cover and not the dunes themselves. The following example illustrates this point.

Figure $11 a$ is a Landsat band 7 image of the Wahiba Sands in Oman. The trends of dunes in the Wahiba Sands dune field do not reflect present-day winds and probably developed in the Pleistocene. The large seif dunes of the Wahiba Sands are "more or less stabilized and have a covering of dikaka" [Glennie, 1970, p. 115] (dikaka is an Arabic word designating scrub-covered dunes). The vegetation is less distinct on the Landsat image than on the SIR image, perhaps because of its state of growth at the time of the Landsat image acquisition (November 1972). Vegetation is bright in band 7 of Landsat MSS. Figure $11 b$ is a SIR-A image of the same area. The incidence angle of the SIR-A system is greater than the angle of respose for dune sand, yet the dunes are recognizable, particularly in the upper part of the image. The bright areas on the SIR-A image are similar in nature to those observed on the $\mathrm{X}$ band image of the Kelso Dunes. Note that regional tonal variations on the SIR-A image are unrelated to the distribution of the dunes; that is, the same dune morphologies have different brightness levels in different parts of the image. Just as in the case of the Kelso Dunes, it is difficult or impossible to map the dune morphology in the darkest (unvegetated) areas on the radar image. It is the vegetation cover which here allows the perception of the dune forms. Conversely, Greeley et al. [1984b] found little evidence of backscatter from desert shrubs and bushes in analysis of SIR-A images of the Pinacate region of Sonora, Mexico. Because the radar backscatter from vegetation is a very strong function of the moisture content (which can vary greatly in deserts), it is not possible to predict a priori the potential contribution desert vegetation may have to the radar backscatter. Considering the observations made here in Figures 10 and 11 and by Greeley et al. [1984b] much caution is indicated in interpretation of radar images of dunes which may be vegetated.

\section{Conclusions and Discussion}

Analysis of radar scatterometer data of sand dunes has established that unvegetated dune surfaces are quasi-specular reflectors at radar wavelengths. This scattering behavior permits a significant signal to be returned to the radar only under certain imaging geometry conditions. The critical geometric constraint documented here is that the incidence angle of the radar beam must be less than or equal to the angle of respose of the dune. If this condition is not met the radar energy is not returned to the antenna, and a dark image results. A second critical geometric constraint was reported by Blom and Elachi [1981]. It was found that the dune trends cannot be parallel to the radar look direction or a dark image results as no radar energy is returned. The strongest radar returns will occur when the dune trend is perpendicular to the radar beam. This effect is difficult to study quanitatively as the angular divergence which still permits a return sufficient to create an image varies with the dune type and the individual dune under consideration. Blom and Elachi [1981] found that certain dunes would return a substantial echo even when the angle between the radar beam and the dune trend was up to $60^{\circ}$ from perpendicular. The divergence angle which would still allow imaging would be much less for a very smooth linear (seif) dune however.

From a radar backscattering point of view, a dune is perhaps best thought of as a collection of smooth, flat surfaces which can have any inclination to the local normal up to about $34^{\circ}$ (with the orientation being a function of the local wind regime). In this way, the fact that the backscatter curves for sand dunes have a broad peak which occurs at some angle less than $34^{\circ}$, but not necessarily zero, is easily understood.

Radar images can be used to map sand dunes provided that the incidence angles are less than the angle of repose $\left(\sim 34^{\circ}\right.$ for terrestrial dunes). At larger incidence angles, sand dunes are very weak scatterers. In this case, mapping of dunes using radar images depends upon their being either outlined by a substrate with a scattering contrast or covered by vegetation or perhaps some other material which scatters sufficiently at larger angles to create an image. Consideration of all the possible sources for backscatter seen in radar images of sand dunes is important to prevent misinterpretations. The implications of the scatterometer data have been amplified by radar images which show these effects.

These results indicate that mapping of dunes on Venus (if dunes are present) with the Venus Radar Mapper system may be impossible at certain latitudes because of incidence angle variation with latitude (higher latitudes will be imaged at lower angles). Current plans indicate about $70 \%$ of the planet will be imaged at incidence angles greater than $30^{\circ}$ [Raney, 1986]. Furthermore, the look directions are constrained by the polar orbit, and any dunes which trend east-west (parallel to the look direction) may be difficult to detect even if the incidence angle is low enough. Also, because Venusian dunes are likely to be somewhat radar transparent, they may appear entirely dark, or the substrate beneath them may be detected instead of the dunes (provided the dune cover is thin enough and the substrate is rough enough). It is clear from the observations made herein that substantial errors are likely in interpretation of radar images of possible aeolian landscapes on the earth, Venus, or elsewhere unless the scattering behavior of such terranes is appreciated. 
Acknowledgments. The authors wish to thank Carol Breed, Pamela Cooley, Tim Dixon, Floyd Sabins, and Ray Sugiura for discussions and help in the field. Ann Sheehan helped with the data reduction, and Sue Salas helped with the graphics. The Earth Resources Branch of the Johnson Space Center acquried the scatterometer and $X$ band data. Manouher Naraghi of the Image Processing Laboratory at the Jet Propulsion Laboratory provided computing assistance. This manuscript was much improved by reviews by Peter Ford and Ronald Greeley. This research was performed at the Jet Propulsion Laboratory of the California Institute of Technology and sponsored by the National Aeronautics and Space Administration.

\section{REFERENCES}

Berlin, G. L., M. A. Tarabzouni, K. M. Sheikho, and A. Al-Nasser, SIR-A and Landsat MSS observations of eolian sand deposits on the Al Labbah Plateau, Saudi Arabia, in Proceedings of Nineteenth International Symposium of Remote Sensing of Environment, vol. 1, pp. 311-321, Environmental Research Institute of Michigan, Ann Arbor, 1985.

Berlin, G. L., M. A. Tarabzouni, A. Al-Nasser, K. M. Sheikho, and R. W. Larson, SIR-B subsurface imaging of a sand-buried landscape: Al Labbah plateau, Saudi Arabia, IEEE Trans. Geosci. Remote Sens., GE-24, 595-602, 1986.

Blom, R., Radar penetration bibliography, report, 16 pp., Jet Propul. Lab., Pasadena, Calif., 1984.

Blom, R. G., and C. Elachi, Spaceborne and airborne imaging radar observations of sand dunes, J. Geophys. Res., 86, 3061-3073, 1981.

Blom, R. G., C. Elachi, and A. S. Sheehan, Radar scatterometry of sand dunes and lava flows, paper presented at IEEE International Geoscience and Remote Sensing Symposium, Inst. of Electr. and Electron. Eng., Munich, West Germany, 1982a.

Blom, R. G., D. Evans, and C. Elachi, Results from OSTA-1: SIR-A images of volcanic fields and sand dunes, paper presented at IEEE International Geoscience and Remote Sensing Symposium, Inst. of Electr. and Electron. Eng., Munich, West Germany, $1982 b$.

Blom, R. G., R. E. Crippen, and C. Elachi, Detection of subsurface features in Seasat radar images of Means Valley, Mojave Desert, California, Geology, 12, 346-349, 1984.

Breed, C. S., Terrestrial analogs to the Hellespontus dunes, Mars, Icarus, 30, 326-340, 1977.

Breed, C. S., M. J. Grolier, and J. F. McCauley, Morphology and distribution of common "sand" dunes on Mars: Comparison with the earth, J. Geophys. Res., 84, 8183-8204, 1979.

Campbell, M. J., and J. Ulrichs, Elecrical properties of rocks and their significance for lunar radar observations, J. Geophys. Res., 74, 5867-5881, 1969.

Clark, B. V., and B. R. Jean, The software system development for the TAMU real time fan beam scatterometer data processors, Final Rep. RSC 3556-2, Remote Sens. Cent., Tex. A \& M Univ., College Station, 1980.

Clark, B. V., and R. W. Newton, Development and evaluation of scatterometer data processing algorithms, Final Rep. RSC 3337, Remote Sens. Cent., Tex. A \& M Univ., College Station, 1979.

Classen, J. P., R. O. Stroud, B. V. Clark, B. R. Jean, and R. W. Newton, The system and hardware design of real time fan beam scatterometer data processors, Final Rep. RSC 3556, Remote Sens. Cent., Tex. A \& M Univ., College Station, 1979.

Cutts, J. A., and R. S. U. Smith, Eolian deposits and dunes on Mars, J. Geophys. Res., 78, 4139-4154, 1973.

DeLoor, G. P., The dielectric properties of wet materials, IEEE Trans. Geosci. Remote Sens., GE-21, 365-369, 1983.

Elachi, C., L. E. Roth, and G. G. Schaber, Spaceborne radar subsurface imaging in hyperarid regions, IEEE Trans. Geosci. Remote Sens., GE-22, 383-388, 1984.

Fung, A., and F. Ulaby, Matter energy interaction in the microwave region, in Manual of Remote Sensing, edited by R. N. Colwell, American Society of Photogrammetry, Falls Church, Va., 1983.

Glennie, K. W., Desert sedimentary environments, Dev. Sedimentol., I4, 222 pp., 1970

Greeley, R., and J. D. Iverson, Wind as a Geological Process, Cambridge University Press, New York, 1985.

Greeley, R, and J. R. Marshall, Transport of Venusian rolling 'stones' by wind?, Nature, 313, 771-773, 1985.

Greeley, R., B. R. White, R. Leach, R. Leonard, J. Pollack, and J. D. Iversen, Venus aeolian processes: Saltation studies and the Venusian wind tunnel, NASA Tech. Memo., TM-82385, 275-277, 1980.

Greeley, R., J. R. Marshall, and R. N. Leach, Microdunes and other eoloian bedforms on Venus: Wind tunnel simulations. Icarus, 60 , 152-160, 1984a.

Greeley, R., P. R. Christensen, J. F. McHone, Y. Asmerom, and J. R. Zimbelman, Analysis of the Gran Desierto-Pinacate Region, Sonora, Mexico, via shuttle imaging radar, NASA CR 175711, 106 pp., $1984 b$.

Hoekstra, P., and A. Delaney, Dielectric properties of soils at UHF and microwave frequencies, J. Geophys. Res., 79, 1699-1708, 1974.

Kerr, D., Propagation of Short Radio Waves, McGraw-Hill, New York, 1951.

McCauley, J. F., G. G. Schaber, C. S. Breed, M. J. Grolier, C. V. Haynes, B. Issawi, C. Elachi, and R. Blom, Subsurface valleys and geoarcheology of eastern Sahara revealed by shuttle radar, Science, 218, 1004-1019, 1982.

McCauley, J. F., C. S. Breed, G. G. Schaber, W. P. McHugh, B. Issawi, C. V. Haynes, M. J. Grolier, and A. El Kilani, Paleodrainages of the Eastern Sahara-The radar rivers revisted (SIR-A/B implications for a mid-Tertiary trans-African drainage system), IEEE Trans. Geosci. Remote Sens., GE-24, 624-648, 1986.

McKee, E. D., (Ed.), A study of global sand seas, U.S. Geol. Surv. Prof. Pap., 1052, 429 pp., 1979.

Raney, R. K., SAR system test and calibration; Magellan Q. Bull., 9, pp. 10-15, Jet Propul. Lab., Pasadena, Calif., Oct. 1986.

Reid, S. C., Joint soil moisture experiment scatterometer systems, Doc. LEC-7195, Lockheed Electron. Co. Inc., 1975.

Ross, R., Radar cross-section of rectangular flat plates as a function of aspect angle, IEEE Trans. Antennas Propag. AP-14, 324-335, 1966.

Sharp, R. P., Measurements on desert dunes-a testing of some concepts, Geol. Soc. Am. Abstr. Programs, 238, 1962

Sharp, R. P., Wind ripples, J. Geol., 7I, 617-636, 1963.

Sharp, R. P., Kelso Dunes, Mojave Desert, California, Geol. Soc. Am. Bull., 77, 1045-1074, 1966.

Sharp, R. P., Intradune flats of the Algodones Chain, Geol. Soc. Am. Bull., 90, 908-916, 1979.

Smith, R. S. U., Barchan dunes in a seasonally reversing wind regime, southeastern Imperial County, California, M.S. thesis, Univ. of Ariz., Tucson, 1970.

Sugiura, R., and F. F. Sabins, Jr., The evaluation of $3 \mathrm{~cm}$ wavelength radar images for mapping surface deposits in the Bristol LakeGranite Mountains area, Mojave Desert, California, Proceedings of Radar Geology Workshop, Snowmass, Colo., JPL Publ., 80-61, 439-456, 1980

Wang, J. R., and T. J. Schmugge, An empirical model for the complex dielectric permittivity of soils as a function of water content, IEEE Trans. Geosci. Remote Sens., GE-18, 288-295, 1980.

White, B. R., Venusian saltation, Icarus, 46, 226-232, 1981.

R. Blom and C. Elachi, Jet Propulsion Laboratory, California Institute of Technology, Pasadena, CA 91109.

(Received January 2, 1986; revised November 18, 1986; accepted January 29, 1987.) 